\title{
Association of air pollution with outpatient visits for respiratory diseases of children in an ex-heavily polluted Northwestern city, China
}

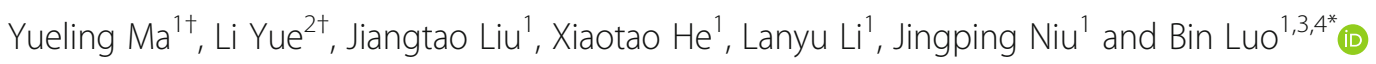

\begin{abstract}
Background: A great number of studies have confirmed that children are a particularly vulnerable population to air pollution.

Methods: In the present study, 332,337 outpatient visits of 15 hospitals for respiratory diseases among children (013 years), as well as the simultaneous meteorological and air pollution data, were obtained from 2014 to 2016 in Lanzhou, China. The generalized additive model was used to examine the effects of air pollutants on children's respiratory outpatient visits, including the stratified analysis of age, gender and season.

Results: We found that $\mathrm{PM}_{2.5}, \mathrm{NO}_{2}$ and $\mathrm{SO}_{2}$ were significantly associated with the increased total respiratory outpatient visits. The increments of total respiratory outpatient visits were the highest in lag 05 for $\mathrm{NO}_{2}$ and $\mathrm{SO}_{2}$, a $10 \mathrm{\mu g} / \mathrm{m}^{3}$ increase in $\mathrm{NO}_{2}$ and $\mathrm{SO}_{2}$ was associated with a $2.50 \%(95 \% \mathrm{Cl}: 1.54,3.48 \%)$ and $3.50 \%(95 \% \mathrm{Cl}: 1.51$, $5.53 \%)$ increase in total respiratory outpatient visits, respectively. Those associations remained stable in twopollutant models. Through stratification analysis, all air pollutants other than $\mathrm{PM}_{10}$ were significantly positive associated with the outpatients of bronchitis and upper respiratory tract infection. Besides, both $\mathrm{NO}_{2}$ and $\mathrm{SO}_{2}$ were positively related to the pneumonia outpatient visits. $\mathrm{PM}_{2.5}$ and $\mathrm{SO}_{2}$ were significantly related to the outpatient visits of other respiratory diseases, while only $\mathrm{NO}_{2}$ was positively associated with the asthma outpatients. We found these associations were stronger in girls than in boys, particularly in younger (0-3 years) children. Interestingly, season stratification analysis indicated that these associations were stronger in the cold season than in the transition or the hot season for $\mathrm{PM}_{10}, \mathrm{PM}_{2.5}$ and $\mathrm{SO}_{2}$.
\end{abstract}

Conclusions: Our results indicate that the air pollution exposure may account for the increased risk of outpatient visits for respiratory diseases among children in Lanzhou, particularly for younger children and in the cold season.

Keywords: Air pollution, Respiratory diseases, Children, Outpatient visit, Time-series study

\footnotetext{
* Correspondence: luob@|zu.edu.cn

${ }^{\dagger}$ Yueling Ma and Li Yue contributed equally to this work.

'Institute of Occupational Health and Environmental Health, School of Public

Health, Lanzhou University, Lanzhou, Gansu 730000, People's Republic of

China

${ }^{3}$ Shanghai Typhoon Institute, China Meteorological Administration, Shanghai 200030, China

Full list of author information is available at the end of the article
}

C C The Author(s). 2020 Open Access This article is licensed under a Creative Commons Attribution 4.0 International License, which permits use, sharing, adaptation, distribution and reproduction in any medium or format, as long as you give appropriate credit to the original author(s) and the source, provide a link to the Creative Commons licence, and indicate if changes were made. The images or other third party material in this article are included in the article's Creative Commons licence, unless indicated otherwise in a credit line to the material. If material is not included in the article's Creative Commons licence and your intended use is not permitted by statutory regulation or exceeds the permitted use, you will need to obtain permission directly from the copyright holder. To view a copy of this licence, visit http://creativecommons.org/licenses/by/4.0/. The Creative Commons Public Domain Dedication waiver (http//creativecommons.org/publicdomain/zero/1.0/) applies to the data made available in this article, unless otherwise stated in a credit line to the data. 


\section{Background}

Air pollution is one of the greatest environmental risks to public health. The World Health Organization (WHO) report showed that outdoor air pollution was responsible for 4.2 million deaths worldwide in 2016 [1]. A growing body of literature has investigated the association between air pollution and respiratory tract, which is the main organ affected by air pollution. For instance, a panel study from Korea suggested that air pollution may cause respiratory symptoms [2]. In addition, a considerable amount of papers have focused on the associations between air pollution and respiratory diseases/ mortality in Europe [3, 4], the United States [5, 6], and some Asian countries [7, 8]. In Taiwan, two main air pollutants $\left(\mathrm{NO}\right.$ and $\mathrm{NO}_{2}$ ) were positively associated with respiratory diseases, followed by $\mathrm{PM}_{10}, \mathrm{PM}_{2.5}, \mathrm{O}_{3}, \mathrm{CO}$ and $\mathrm{SO}_{2}$ [9]. A study with urban Chinese population found that per $10 \mu \mathrm{g} / \mathrm{m}^{3}$ increase in $\mathrm{PM}_{2.5}$ and $\mathrm{PM}_{10}$ concentration on the current day of exposure was associated with 0.36 and $0.33 \%$ increase in respiratory system disease, respectively [10]. In Hangzhou, outpatient visits of adults with respiratory disease increased by $0.67,3.50$ and $2.10 \%$ with per $10 \mu \mathrm{g} / \mathrm{m}^{3}$ increase in $\mathrm{PM}_{2.5}, \mathrm{SO}_{2}$ and $\mathrm{NO}_{2}$, respectively, however, children outpatient visits increased by $1.47,5.70$ and $4.04 \%$, respectively, which indicated that children were more susceptible to air pollutants [11]. Besides, the results for a study in Taiwan showed significant relationships between $\mathrm{NO}_{2}, \mathrm{PM}_{10}$ and asthma outpatients, especially for children [12]. Therefore, air pollution may affect the respiratory outpatient visits.

Children have relatively immature lungs and immune system, and inhale a larger volume of air per body weight [13], so they are more susceptible to the adverse respiratory effects of air pollution. Exposure to air pollution at early stage may affect children's normal growth and lung development $[14,15]$. The increased prevalence of young children's respiratory diseases was also related to air pollution exposure time and dose in Jinan [16]. Particularly, air pollution was positively related to the pneumonia among children $[17,18]$. Besides, better air quality has been approved to reduce respiratory symptoms among children [19]. However, research about comprehensive comparison of respiratory health changes in children from different subgroups is still limited, especially in cities that suffer from heavy air pollution.

Air pollution is a global problem. About $91 \%$ of the world population was estimated to breathe polluted air which exceeded the WHO air quality guideline levels in 2016 [20]. Lanzhou, an industrial city, located in a typical valley basin, is particularly well known as a dry city with scarce rainfall, high evaporation and low wind speeds [21]. Moreover, it is also frequently affected by dust storms due to its location closed to the arid and semi-arid region of Northwest China [22]. These factors combine to make Lanzhou one of the most traditional seriously air-polluted cities in China. Although, a study with very limited data has reported the effect of $\mathrm{PM}_{2.5}$ over respiratory disease in Lanzhou, but didn't focus on the children [21]. Normally, children are often divided into young children period ( $0-3$ years age), preschool period (4-6 years age) and school period (7-13 years age), displaying growing level of immunity, who may show different effects when exposed to air pollution [23]. Therefore, we aim to assess the effects of air pollutants on children's outpatient visits for respiratory diseases from different subgroups with the data of 15 hospitals in a poor area of China-Lanzhou city.

\section{Methods}

Study area and data collection

Being the capital city of Gansu province, Lanzhou is located in the north-west of China with a population of over 3.7 million in 2017 [24]. Lanzhou is one of the most airpolluted cities in China, because it is heavily industrialized and owns a valley style terrain, and has a typical semi-arid continental climate with scarce precipitation [21, 25]. Even though the authorities have taken significant measures to improve the air quality in Lanzhou, the level of air pollutants concentration (The average annual $\mathrm{PM}_{2.5}, \mathrm{PM}_{10}, \mathrm{SO}_{2}$ and $\mathrm{NO}_{2}$ concentrations during 2007-2016 in Lanzhou were $61.23 \mu \mathrm{g} / \mathrm{m}^{3}, 136.14 \mu \mathrm{g} / \mathrm{m}^{3}, 42.93 \mu \mathrm{g} / \mathrm{m}^{3}$ and $45.37 \mu \mathrm{g} / \mathrm{m}^{3}$, respectively.) [21] exceeded the national level II (The average annual standards for $\mathrm{PM}_{2.5}$ is $35 \mu \mathrm{g} / \mathrm{m}^{3}, \mathrm{PM}_{10}$ is $70 \mu \mathrm{g} / \mathrm{m}^{3}$, $\mathrm{SO}_{2}$ is $60 \mu \mathrm{g} / \mathrm{m}^{3}$, and $\mathrm{NO}_{2}$ is $40 \mu \mathrm{g} / \mathrm{m}^{3}$.).

The daily number of outpatients for respiratory diseases between 2014 and 2016 were obtained from the 15 hospitals of the four central urban districts of Lanzhou (Chengguan, Qilihe, Xigu and Anning) (Fig. 1), which was confirmed and permitted by the Lanzhou center for disease control and prevention. This study protocol was approved by the ethics committee of Lanzhou University (Project identification code: IRB190612-1). We screened the outpatient visit data using the 10th Revision of the International Classification of Diseases (ICD-10) Code of respiratory diseases (J00-J99). We excluded the patients who were not living in the four central urban districts of Lanzhou and those children aged $\geq 14$ years. Finally, all outpatient data were classified into four specific diseases [pneumonia, J12-J18; asthma, J45-J46; bronchitis and upper respiratory tract infection (J00-J06, J20-J21, J30-J39, J40-J42); and other respiratory diseases (J22, J43-J44, J47, J60-J99)].

The simultaneous daily meteorological variables and air pollutants data were obtained from open access website of Lanzhou Meteorological administration and Lanzhou air quality monitoring stations (including Institute of Biology, Railway design institute, Hospital of Staff 


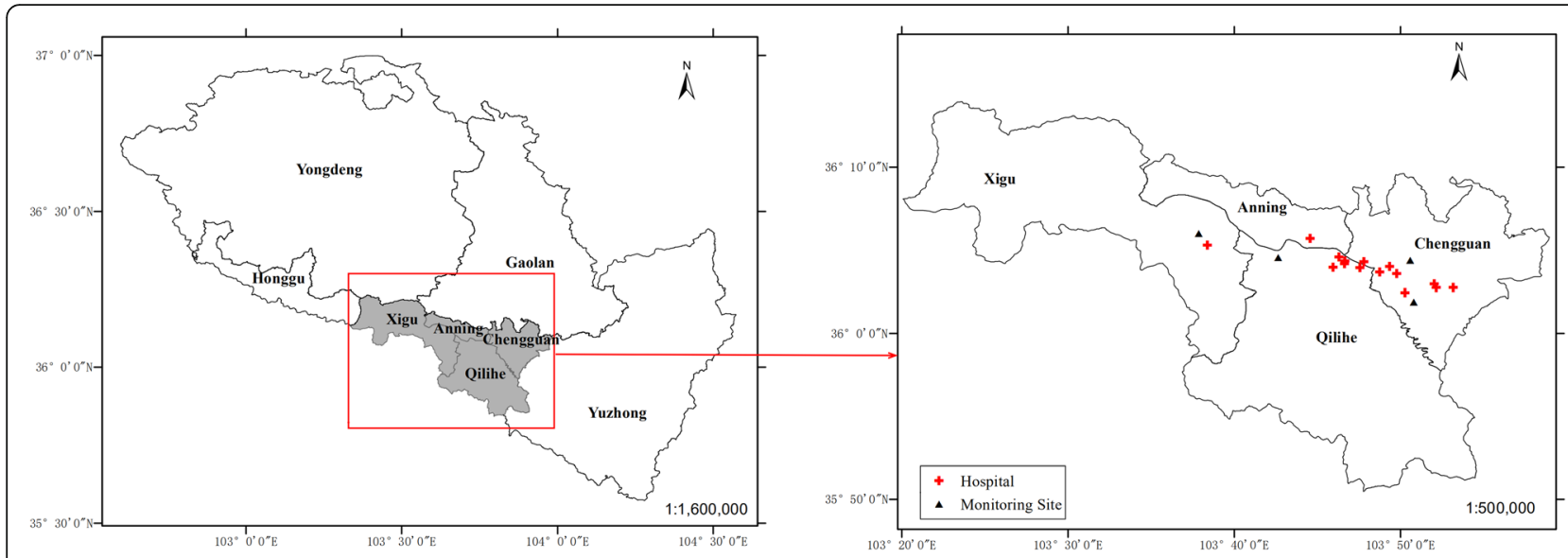

Fig. 1 Spatial distribution of air quality monitoring stations, studied hospitals, and four central urban districts in Lanzhou, China. Source: The map was created by the authors with ArcGIS 10.2.2 software (ESRI, Redlands, California, USA). ArcGIS is the intellectual property of ESRI and is used by license in here

and LanLian Hotel) (Fig. 1), respectively. The air quality monitoring stations were in four central urban districts of Lanzhou. Meteorological variables included daily average temperature and relative humidity, and air pollutants data included particulate matter with aerodynamic diameter $\leq 10 \mu \mathrm{m} \quad\left(\mathrm{PM}_{10}\right)$, particulate matter with aerodynamic diameter $\leq 2.5 \mu \mathrm{m}\left(\mathrm{PM}_{2.5}\right)$, nitrogen dioxide $\left(\mathrm{NO}_{2}\right)$ and sulfur dioxide $\left(\mathrm{SO}_{2}\right)$.

\section{Statistical methods}

The descriptive analysis was performed for all data. The Quasi-Poisson regression with generalized additive model (GAM) was used to examine the associations between air pollutants $\left(\mathrm{PM}_{10}, \mathrm{PM}_{2.5}, \mathrm{NO}_{2}\right.$ and $\left.\mathrm{SO}_{2}\right)$ and the daily children's outpatient visits with respiratory diseases. The Quasi-Poisson distribution was applied to overcome the overdispersion of outpatient visits data. Generalized additive model allows for highly flexible fitting as the outcome is supposed to be dependent on a sum of the smoothed and linear functions of the predictor variables [26]. Based on the previous studies, the penalized smoothing spline function was used to adjust for long-term time trends, day-of-week, holiday and meteorological factors [27, 28]. The basis GAM equation is:

$$
\begin{gathered}
\log \mathrm{E}\left(Y_{t}\right)=\alpha+\beta X_{t}+s(\text { Time }, k=d f+1)+s\left(\text { Temperature }_{l}, k=d f+1\right) \\
+s\left(\text { Humidity }_{l}, k=d f+1\right)+D O W+\text { Holiday }^{\prime}
\end{gathered}
$$

Where $t$ is the day of the observation; $E\left(Y_{t}\right)$ is the expected number of daily outpatient visits for respiratory diseases on day $\mathrm{t} ; \alpha$ is the intercept; $\beta$ is the regression coefficient; $X_{t}$ is the daily concentration of air pollutant on day $\mathrm{t}$; $\mathrm{s}()$ denotes the smoother based on the penalized smoothing spline; The same lag structures as pollutants for temperature and relative humidity are adjusted, and Temperature ${ }_{1}$ and Humidity ${ }_{1}$ are the six-day moving average (lag 05) of temperature and relative humidity, respectively [27, 29]. Based on Akaike's information criterion (AIC), the 7 degrees of freedom $(d f)$ per year is used for long-term time trends and $3 \mathrm{df}$ for Temperature ${ }_{1}$ and Humidityl; DOW is a categorical variable indicating the date of the week; and holiday is a binary variable for national holiday in China.

After constructing the basic model, single-pollutant models were used to examine the lagged effects, i.e., single day lag (from lag 0 to lag 5) and multiple-day average lag (from lag 01 to lag 05). A spline function of GAM was applied to plot the exposure and response correlation curves between air pollution and outpatient visits for respiratory diseases. Moreover, two-pollutant models were set to evaluate the robustness of our results after adjusting for the other pollutants. In stratification analysis, all of these outpatients were classified into different sex (boys and girls) and age (0-3 years, 4-6 years and 713 years), and season [cold season (November to March), hot season (June to August) and transition season (April, May, September and October)] [23, 30]. According to the AIC and previous studies [23, 31], the $d f$ of time was 3, 2, 3 per year for the cold, hot and transition season, respectively. We also conducted a sensitivity analysis by changing the $d f$ from 5 to 9 per year for calendar time and from 3 to 8 for temperature and relative humidity.

All the statistical analyses were two-sided, and at a 5\% level of significance. All analyses were conducted using $\mathrm{R}$ software (version 3.5.2) with the GAM fitted by the "mgcv" package (version 1.8-26). The effect estimates were denoted as the percentage changes and their 95\% confidence intervals (CIs) in daily children's outpatient visits for respiratory diseases associated with per $10 \mu \mathrm{g} /$ $\mathrm{m}^{3}$ increase in air pollutant concentrations. The ArcGIS 
10.2.2 software (ESRI, Redlands, California, USA) and GraphPad Prism 7.00 software were used to plot the Figures.

\section{Results}

Descriptive of air pollutants, meteorological variables and respiratory diseases outpatient data

There were 332,337 respiratory diseases outpatient visits for children during January 1st, 2014 through December 31st, 2016 in 15 major hospitals of Lanzhou. The mean concentrations of $\mathrm{PM}_{2.5}, \mathrm{PM}_{10}, \mathrm{SO}_{2}$ and $\mathrm{NO}_{2}$ were $54.52 \mu \mathrm{g} / \mathrm{m}^{3}, 123.35 \mu \mathrm{g} / \mathrm{m}^{3}, 22.97 \mu \mathrm{g} / \mathrm{m}^{3}$ and $51.80 \mu \mathrm{g} / \mathrm{m}^{3}$ during 2014-2016, respectively. In addition, the median of temperature and relative humidity were $12.9^{\circ} \mathrm{C}$ and $50 \%$, respectively (Table 1 ). On average, there were approximately 303 respiratory diseases outpatient visits per day in our study areas, and the bronchitis and upper respiratory tract infection, boys, children aged 4-6 and 713 years, and cold season had higher visits than other groups (Table 2).

Figure 2 showed that daily air pollutant concentrations were higher in the cold season than in the hot season, such as, the interquartile range of $\mathrm{PM}_{10}, \mathrm{PM}_{2.5}, \mathrm{NO}_{2}$ and $\mathrm{SO}_{2}$ concentrations in the cold season were $70.20 \mu \mathrm{g} / \mathrm{m}^{3}$, $41.00 \mu \mathrm{g} / \mathrm{m}^{3}, 32.20 \mu \mathrm{g} / \mathrm{m}^{3}$ and $20.00 \mu \mathrm{g} / \mathrm{m}^{3}$, respectively, while they were $37.10 \mu \mathrm{g} / \mathrm{m}^{3}, 15.20 \mu \mathrm{g} / \mathrm{m}^{3}, 22.90 \mu \mathrm{g} / \mathrm{m}^{3}$ and $9.50 \mu \mathrm{g} / \mathrm{m}^{3}$ in the hot season. What's more, the trend of total respiratory outpatient visits in different seasons were similar to the daily air pollutant concentrations.

\section{Associations between air pollutants and outpatient visits for respiratory diseases}

In Fig. 3, we observed significantly positive associations between respiratory diseases outpatient visits and the concentration of $\mathrm{NO}_{2}$ and $\mathrm{SO}_{2}$. In single-pollutant models, we found $\mathrm{PM}_{2.5}, \mathrm{NO}_{2}$ and $\mathrm{SO}_{2}$ were significantly associated with the increased respiratory outpatient visits (Fig. 4). Each $10 \mu \mathrm{g} / \mathrm{m}^{3}$ increase of $\mathrm{PM}_{2.5}$ was only significantly associated with total respiratory outpatient visits in lag 0 , lag 01 and lag 02 . The increments of respiratory outpatient visits were the highest in lag 05 for $\mathrm{NO}_{2}$ and $\mathrm{SO}_{2}$. The respiratory outpatient visits in lag 05 increased by $2.50 \%(95 \% \mathrm{CI}: 1.54,3.48 \%)$ and $3.50 \%$ (95\% CI: $1.51,5.53 \%$ ) with per $10 \mu \mathrm{g} / \mathrm{m}^{3}$ increase in $\mathrm{NO}_{2}$ and $\mathrm{SO}_{2}$, respectively. In cause-specific analysis, $\mathrm{PM}_{2.5}$ showed significant effects on the increase of respiratory outpatient visits due to bronchitis and upper respiratory tract infection, and other respiratory diseases, but the significant effect of $\mathrm{PM}_{10}$ was not observed in any type of respiratory diseases (Fig. 5). To $\mathrm{NO}_{2}$, the significantly positive associations were attributed to pneumonia, asthma, and bronchitis and upper respiratory tract infection, with the greatest increase [1.73\% (95\% CI: 0.37 , $3.11 \%$ ) in lag $04,3.28 \%$ (95\% CI: $0.71,5.91 \%$ ) and $2.60 \%$ (95\% CI: $1.59,3.63 \%$ ) in lag 05] in their outpatient visits, respectively. Moreover, for $\mathrm{SO}_{2}$, we found the significantly positive associations in pneumonia, bronchitis and upper respiratory tract infection, and other respiratory diseases in lag 05 .

After sex stratification, we found the effects of $\mathrm{PM}_{10}$ on respiratory outpatient visits for both boys and girls were not statistically significant (Fig. 6). However, the increase of each $10 \mu \mathrm{g} / \mathrm{m}^{3}$ in $\mathrm{PM}_{2.5}$ was only significantly associated with respiratory outpatient visits for boys in lag 0 , but for girls in lag 0, lag 01, lag 02 and lag 03 . Each $10-\mu \mathrm{g} / \mathrm{m}^{3}$ increment of $\mathrm{NO}_{2}$ and $\mathrm{SO}_{2}$ was positively associated with respiratory outpatient visits for boys, with the greatest increase in lag 05 [2.46\% (95\% CI: $1.46,3.46 \%)$ and $3.25 \%$ (95\% CI: $1.20,5.34 \%)$, respectively, and girls, with the greatest increase in lag 05 [2.58\% (95\% CI: $1.50,3.67 \%)$ and 3.89\% (95\% CI: 1.66 , $6.16 \%$ ), respectively. In different ages, $\mathrm{NO}_{2}$ and $\mathrm{SO}_{2}$ were positively related to respiratory outpatient visits for all ages, but $\mathrm{PM}_{2.5}$ only in children aged $0-3$ and 7-13 years (Fig. 7). The effect of $\mathrm{NO}_{2}$ was the highest among $0-3$ years children in lag 05 [3.45\% (95\% CI: 2.37 , $4.54 \%)]$. Meanwhile, the maximum increase of respiratory outpatient visits due to a $10 \mu \mathrm{g} / \mathrm{m}^{3}$ increase of $\mathrm{SO}_{2}$ occurred in lag 05 in children aged $0-3$ [4.67\% (95\% CI:

Table 1 Descriptive statistics on daily air pollutants and meteorological parameters

\begin{tabular}{|c|c|c|c|c|c|}
\hline Variables & Mean (SD) & $P_{25}$ & $P_{50}$ & $P_{75}$ & Range \\
\hline \multicolumn{6}{|l|}{ Air pollutants $\left(\mu \mathrm{g} / \mathrm{m}^{3}\right)$} \\
\hline $\mathrm{PM}_{2.5}$ & $54.52(28.42)$ & 36.01 & 46.60 & 66.52 & $7.15-299.06$ \\
\hline $\mathrm{PM}_{10}$ & $123.35(75.69)$ & 82.39 & 108.36 & 144.88 & $19.72-1207.13$ \\
\hline $\mathrm{SO}_{2}$ & $22.97(15.06)$ & 11.47 & 19.06 & 31.12 & $3.47-130.59$ \\
\hline $\mathrm{NO}_{2}$ & $51.80(21.26)$ & 36.07 & 49.34 & 63.26 & $12.25-138.15$ \\
\hline \multicolumn{6}{|l|}{ Meteorological parameters } \\
\hline Temperature $\left({ }^{\circ} \mathrm{C}\right)$ & $11.40(9.75)$ & 2.58 & 12.90 & 19.70 & $-12.40-29.80$ \\
\hline Relative humidity (\%) & $50.58(14.57)$ & 39.00 & 50.00 & 61.00 & $16.00-88.00$ \\
\hline
\end{tabular}

$S D$ standard deviance, $P_{25}$ 25th percentile, $P_{50}$ 50th percentile, $P_{75} 75$ th percentile, $P M_{2.5}$ particulate matter with aerodynamic diameter $\leq 2.5 \mu$ m, $P M_{10}$ particulate matter with aerodynamic diameter $\leq 10 \mu \mathrm{m}, \mathrm{NO}_{2}$ nitrogen dioxide, $\mathrm{SO}_{2}$ sulfur dioxide 
Table 2 Descriptive statistics on daily outpatient visits in Lanzhou, China, during 2014-2016

\begin{tabular}{|c|c|c|c|c|c|c|}
\hline Variables & Mean \pm SD & Min & $P_{25}$ & $P_{50}$ & $P_{75}$ & Max \\
\hline \multicolumn{7}{|l|}{ Outpatient visits (cases/per day) } \\
\hline Total & $303.23 \pm 97.97$ & 95.00 & 234.00 & 292.00 & 357.00 & 732.00 \\
\hline Pneumonia & $21.48 \pm 15.77$ & 0.00 & 10.00 & 17.00 & 28.00 & 95.00 \\
\hline Asthma & $8.49 \pm 5.43$ & 0.00 & 5.00 & 7.00 & 11.00 & 36.00 \\
\hline Bronchitis and upper respiratory tract infection & $265.28 \pm 83.04$ & 85.00 & 209.00 & 260.00 & 312.00 & 668.00 \\
\hline Other respiratory diseases & $7.98 \pm 5.72$ & 0.00 & 4.00 & 7.00 & 11.00 & 37.00 \\
\hline \multicolumn{7}{|l|}{ Sex } \\
\hline Boys & $174.43 \pm 55.32$ & 42.00 & 135.00 & 170.50 & 205.00 & 418.00 \\
\hline Girls & $128.79 \pm 44.38$ & 42.00 & 97.00 & 124.00 & 154.00 & 314.00 \\
\hline \multicolumn{7}{|l|}{ Age (years) } \\
\hline $0-3$ & $28.45 \pm 42.42$ & 0.00 & 0.00 & 6.00 & 49.00 & 229.00 \\
\hline $4-6$ & $136.33 \pm 42.76$ & 43.00 & 103.00 & 134.00 & 167.00 & 262.00 \\
\hline $7-13$ & $138.45 \pm 58.27$ & 24.00 & 95.00 & 133.00 & 173.00 & 423.00 \\
\hline \multicolumn{7}{|l|}{ Season } \\
\hline Cold (Nov to Mar) & $351.60 \pm 115.54$ & 95.00 & 266.25 & 355.00 & 422.75 & 732.00 \\
\hline Transition (Apr, May, Sep and Oct) & $285.93 \pm 50.26$ & 163.00 & 252.00 & 283.00 & 322.00 & 444.00 \\
\hline Hot (Jun to Aug) & $246.60 \pm 73.46$ & 114.00 & 190.00 & 233.50 & 297.25 & 442.00 \\
\hline
\end{tabular}

$1.22,8.24 \%)]$. In addition, the greatest increment of respiratory outpatient visits was occurred in lag 05 with a $10 \mu \mathrm{g} / \mathrm{m}^{3}$ increase of $\mathrm{PM}_{10}$ [0.60\% (95\% CI: 0.21, 0.99\%)], $\mathrm{PM}_{2.5}[2.52 \%$ (95\% CI: $\left.1.45,3.60 \%)\right]$ and $\mathrm{SO}_{2}[7.95 \%$ (95\% CI: $5.40,10.55 \%)]$ in the cold season, but $\mathrm{NO}_{2}$ [4.02\% (95\% CI: 2.08, 5.99\%)] in the transition season (Fig. 8). The positive associations were observed among air pollutants, including $\mathrm{PM}_{2.5}$ with $\mathrm{PM}_{10}(r=0.73), \mathrm{SO}_{2}$ $(r=0.60)$ and $\mathrm{NO}_{2}(r=0.57)$; and $\mathrm{PM}_{10}$ with $\mathrm{SO}_{2}(r=$
0.33) and $\mathrm{NO}_{2} \quad(r=0.39) ; \mathrm{SO}_{2}$ with $\mathrm{NO}_{2} \quad(r=0.53)$ (Table 3).

After the optimum lag day for each pollutant being determined in the single-pollutant models, the twopollutant models were used to adjust for other pollutants. Table 4 compared the results of the singlepollutant models with the results of the two-pollutant models using exposure in lag 05 after adjusting for other pollutants. After adjusting for $\mathrm{PM}_{10}$ and $\mathrm{PM}_{2.5}$

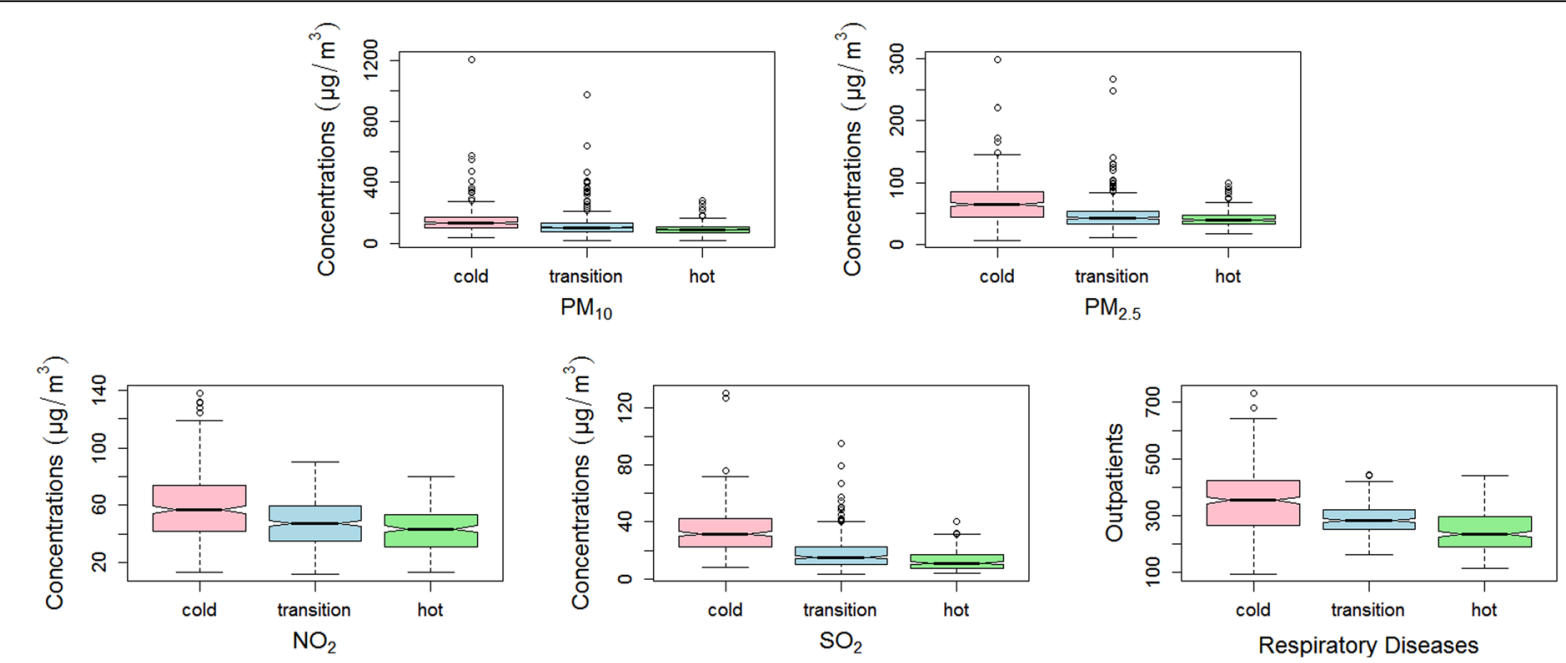

Fig. 2 Box plots of air pollutants and total outpatients with respiratory diseases in the cold, transition and hot season. Boxes indicate the interquartile range (25th percentile-75th percentile); lines within boxes indicate medians; whiskers below boxes represent minimum values; whiskers and dots above boxes indicate maximum values. $\mathrm{PM}_{2.5}$, particulate matter with aerodynamic diameter $\leq 2.5 \mu$ m; $\mathrm{PM}_{10}$, particulate matter with aerodynamic diameter $\leq 10 \mu \mathrm{m} ; \mathrm{NO}_{2}$, nitrogen dioxide; $\mathrm{SO}_{2}$, sulfur dioxide 

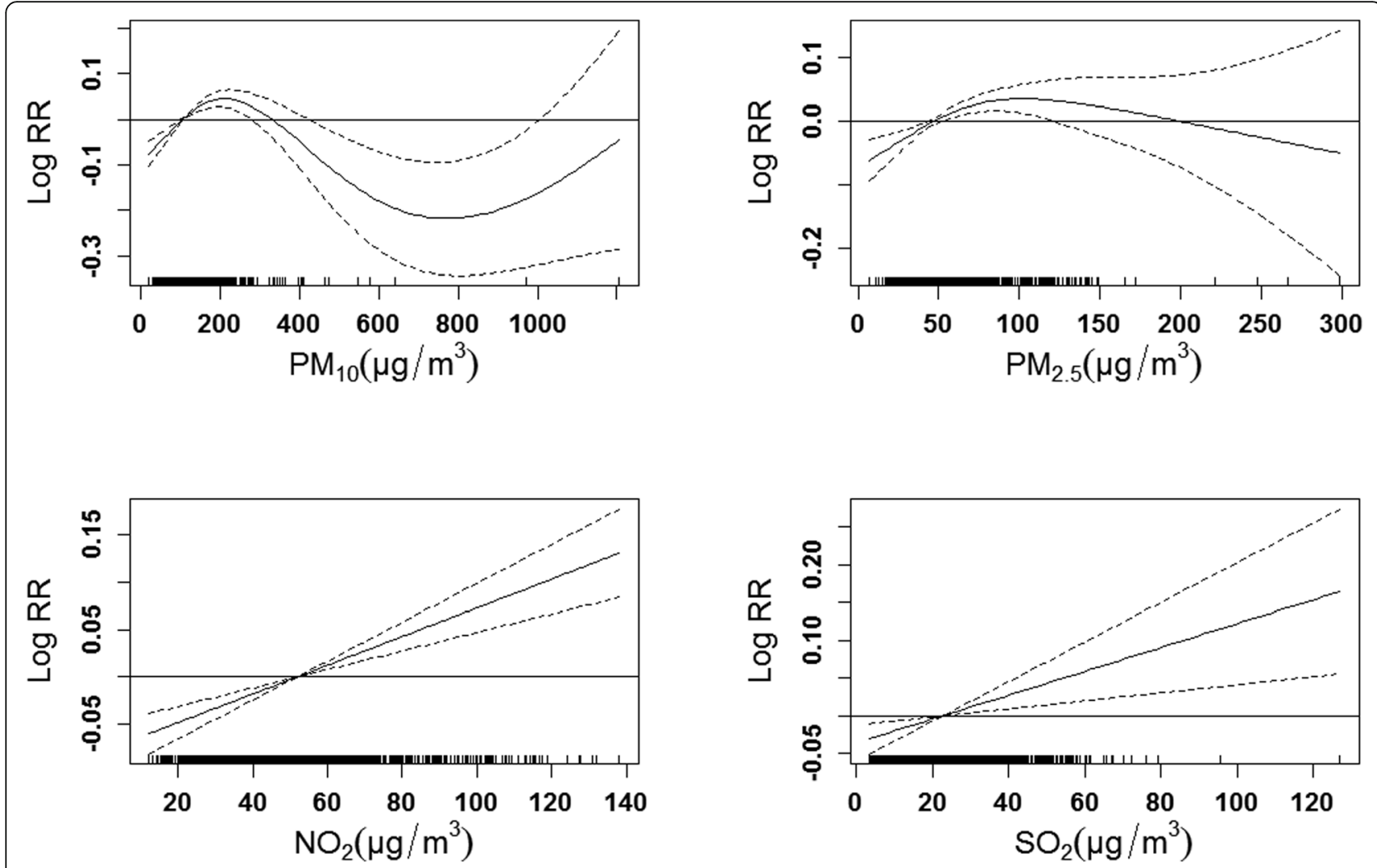

Fig. 3 The exposure-response curves of air pollutants concentrations and total outpatients with respiratory diseases in Lanzhou, China, during 2014-2016. The $X$-axis is the concurrent day air pollutants concentrations $\left(\mu \mathrm{g} / \mathrm{m}^{3}\right), Y$-axis is the predicted log relative risk (RR), is shown by the solid line, and the dotted lines represent the $95 \%$ confidence interval (CI). $\mathrm{PM}_{2.5}$, particulate matter with aerodynamic diameter $\leq 2.5 \mu \mathrm{m} ; \mathrm{PM}_{10}$, particulate matter with aerodynamic diameter $\leq 10 \mu \mathrm{m} ; \mathrm{NO}_{2}$, nitrogen dioxide; $\mathrm{SO}_{2}$, sulfur dioxide

concentration in the two-pollutant models, the percentage increase for total respiratory diseases outpatient visits of $\mathrm{NO}_{2}$ and $\mathrm{SO}_{2}$ remained statistically significant with a little increase. However, after controlling $\mathrm{NO}_{2}$ and $\mathrm{SO}_{2}$, we found the percentage changes of $\mathrm{PM}_{2.5}$ and $\mathrm{PM}_{10}$ were not statistically associated with total respiratory diseases outpatient visits, similar to the results of the single-pollutant models.

\section{Discussion}

Lanzhou has a population of over 3.7 million with children accounting for 14\% in 2016 [32]. In this study, we observed 332,337 children's outpatient visits for respiratory diseases within 3 years, suggesting respiratory diseases is a major health problem among children in Lanzhou. Many studies about air pollution and children respiratory diseases were conducted in the cities of China with moist climate, such as Shenzhen [33], Hefei [34] and so on. However, research about comprehensive comparison of air pollution at respiratory diseases of different groups (gender, age, season and cause-specific diseases) is still limited, especially in city with arid climate. Therefore, our results may add to the limited scientific knowledge that air pollution may also affect the incidence of respiratory diseases among children from different subgroups in an arid climate city.

The results showed that $\mathrm{PM}_{2.5}, \mathrm{NO}_{2}$ and $\mathrm{SO}_{2}$ were significantly associated with the increased total respiratory outpatient visits of children. A study in Shanghai during 2013-2015 found that an interquartile range (IQR) increase in $\mathrm{PM}_{2.5}, \mathrm{SO}_{2}$ and $\mathrm{NO}_{2}$ was associated with a $8.81,17.26$ and $17.02 \%$ increase for daily pediatric respiratory emergency visits in lag 03, respectively [35], which is higher than our study. The possible explanation is that the air pollution level in Shanghai of 2013-2015 showed a trend of rising, but it has been persistently declining in Lanzhou since 2013 [36]. However, a study conducted in Yichang during 2014-2015, China, observed that each IQR increase in $\mathrm{PM}_{2.5}$ and $\mathrm{NO}_{2}$ concentrations corresponded to a 1.91 and $1.88 \%$ increase of pediatric respiratory outpatient visits at current day, respectively [37], which was higher for $\mathrm{PM}_{2.5}$ but lower than our study for $\mathrm{NO}_{2}$. It is because that the daily average concentration of $\mathrm{PM}_{2.5}$ in Yichang was higher $\left(84.9 \mu \mathrm{g} / \mathrm{m}^{3}\right.$ VS $\left.54.52 \mu \mathrm{g} / \mathrm{m}^{3}\right)$ but $\mathrm{NO}_{2}$ was lower than Lanzhou $\left(37.4 \mu \mathrm{g} / \mathrm{m}^{3}\right.$ VS $\left.51.80 \mu \mathrm{g} / \mathrm{m}^{3}\right)$ [37]. However, the associations between $\mathrm{PM}_{10}$ and total respiratory 
(A) $\mathbf{P M}_{10}$

Total

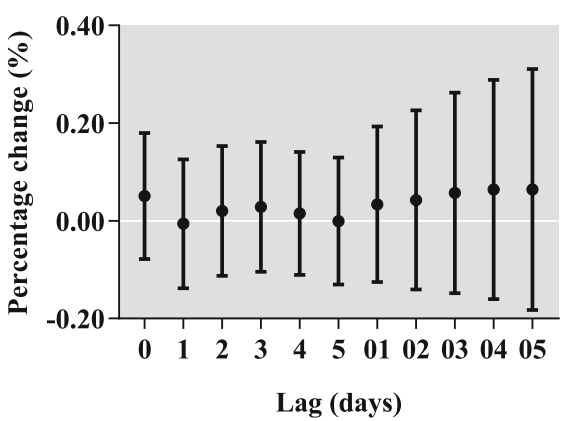

(C) $\mathrm{NO}_{2}$

Total

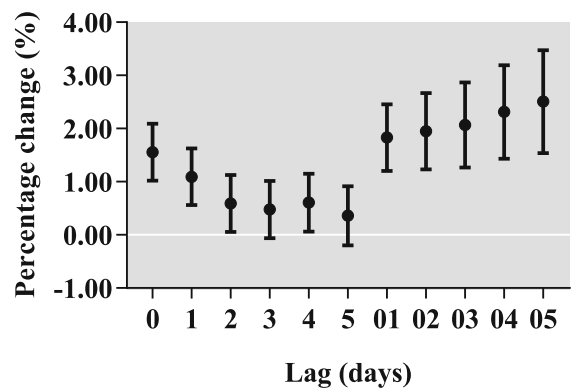

(B) $\mathbf{P M}_{2.5}$

Total

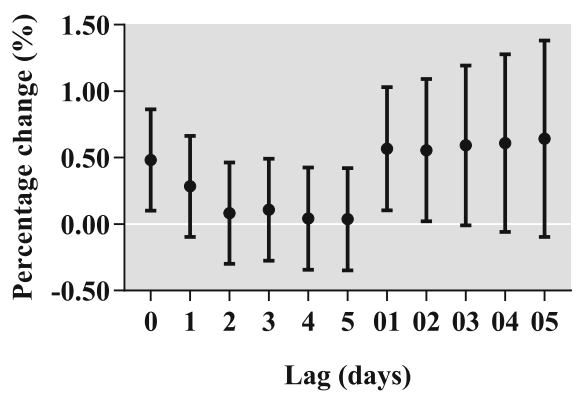

(D) $\mathrm{SO}_{2}$

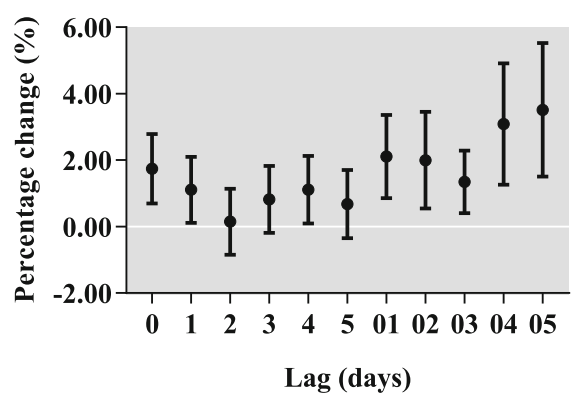

Fig. 4 Percentage change (95\% confidence interval) of children outpatient visits for total respiratory diseases per $10 \mu \mathrm{g} / \mathrm{m}^{3}$ increase in concentrations of air pollutants for different lag days in the single-pollutant models in Lanzhou, China, during 2014-2016. PM P.5, $_{2}$ particulate matter with aerodynamic diameter $\leq 2.5 \mu \mathrm{m} ; \mathrm{PM}_{10}$, particulate matter with aerodynamic diameter $\leq 10 \mu \mathrm{m} ; \mathrm{NO}_{2}$, nitrogen dioxide; $\mathrm{SO}_{2}$, sulfur dioxide

outpatients were insignificant, which is not consistent with the findings from other studies [35, 37]. Shanghai is characterized by a higher degree of urbanization and industrialization than Lanzhou, so the $\mathrm{PM}_{10}$ of which mainly comes from traffic and industry pollution sources, similar to that in Yichang $[36,38]$. However, the $\mathrm{PM}_{10}$ in Lanzhou was mainly contributed by raised dust containing higher level of crustal elements, which is not as poisonous as that in Shanghai and Yichang [39]. Even so, our results indicate that the air pollution is positively related to the respiratory diseases among children in Lanzhou.

It is well known that air pollutants are the risk factors for many respiratory diseases in children. An eight-year time-series study in Hanoi showed that all air pollutants $\left(\mathrm{PM}_{10}, \mathrm{PM}_{2.5}, \mathrm{NO}_{2}\right.$ and $\left.\mathrm{SO}_{2}\right)$ were positively associated with pneumonia, bronchitis and asthma hospitalizations among children [18], like that reported in Shijiazhuang [23] and Taiwan [9]. Consistent with these studies, we also found all air pollutants (except $\mathrm{PM}_{10}$ ) were positively related to the outpatient visits of bronchitis and upper respiratory tract infection. Coupled with the fact that bronchitis and upper respiratory tract infection were the major types of respiratory diseases $(87.45 \%$ of all respiratory outpatient visits) in Lanzhou, the effect of air pollution may explain part of this phenomenon. To asthma, gas pollutant like $\mathrm{NO}_{2}$ has been well known as its major risk factor, which has also been confirmed in a study with a broad range of exposures and diverse populations among children published in the Lancet [40]. Unfortunately, similar result was also found in our study with an arid climate. Therefore, although the Lanzhou government has worked positively and gained great international compliment in reducing the air pollution [41], more efforts will be needed to reduce the air pollution from vehicle exhaust.

In the stratified analysis, the impact of air pollution was more significant on girls than boys, which is consistent with the study in Taiwan among the children respiratory outpatients [9]. A review showed that girls had smaller lungs, shorter and wider airways, and exhibited higher forced expiratory flow rates than boys [42]. Therefore, the airways of girls may be less able to block 

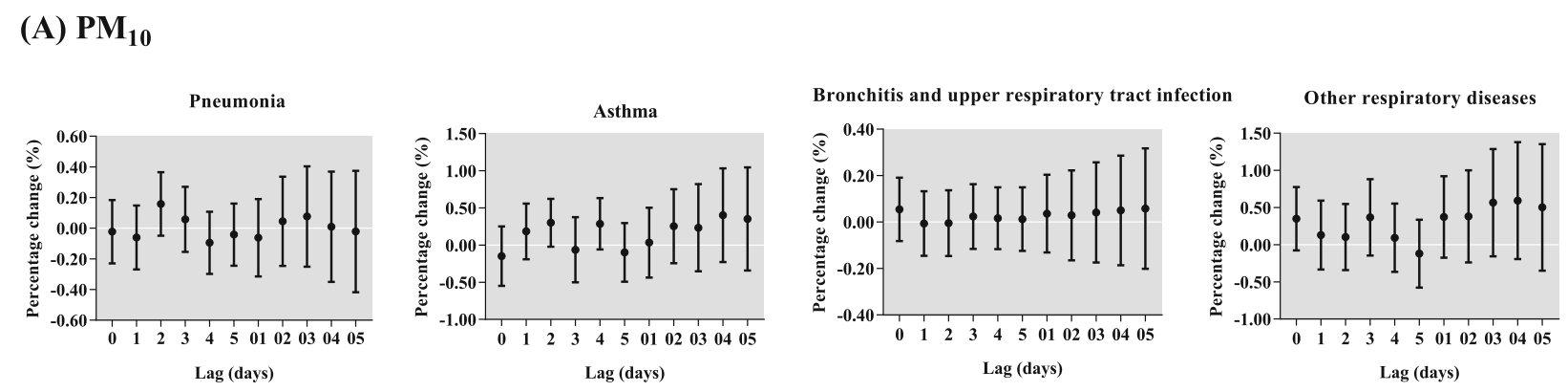

(B) $\mathrm{PM}_{2.5}$
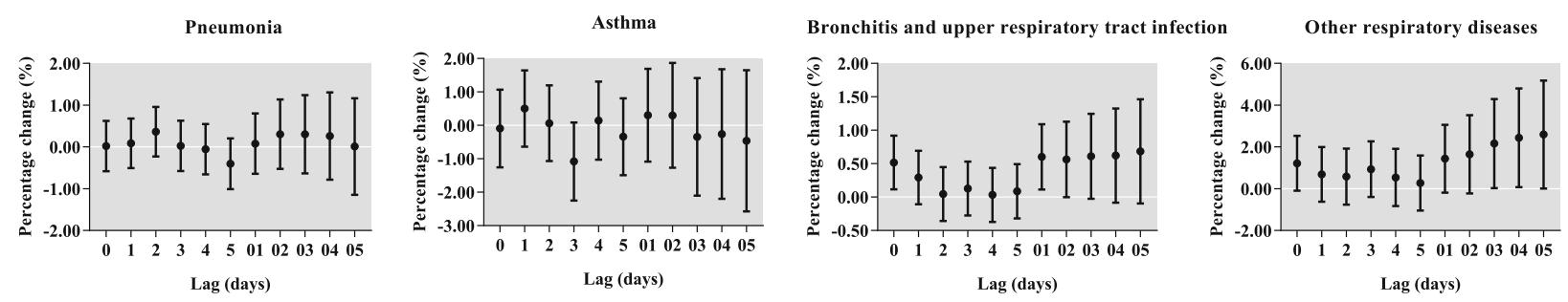

\section{(C) $\mathrm{NO}_{2}$}
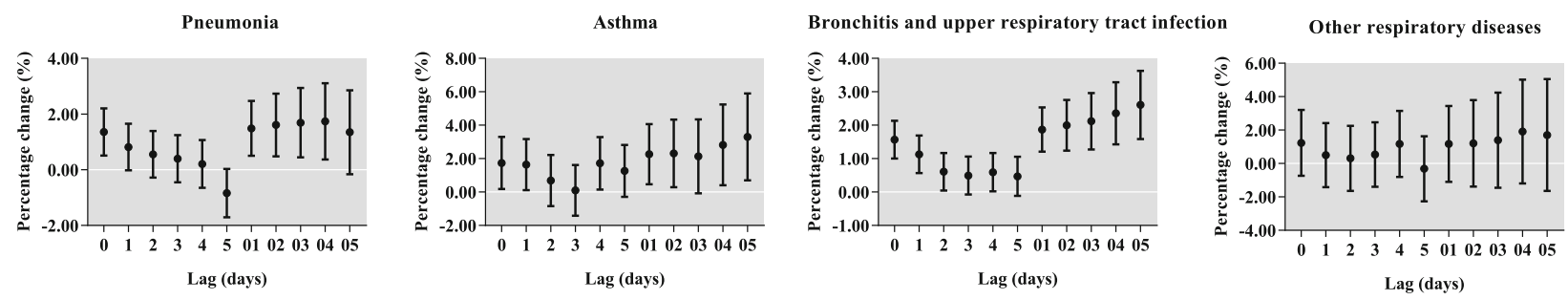

(D) $\mathrm{SO}_{2}$


Fig. 5 Percentage change (95\% confidence interval) of children outpatient visits for cause-specific respiratory diseases per $10 \mu \mathrm{g} / \mathrm{m}^{3}$ increase in concentrations of air pollutants for different lag days in the single-pollutant models in Lanzhou, China, during 2014-2016. PM 2.5 , particulate matter with aerodynamic diameter $\leq 2.5 \mu \mathrm{m} ; \mathrm{PM}_{10}$, particulate matter with aerodynamic diameter $\leq 10 \mu \mathrm{m} ; \mathrm{NO}_{2}$, nitrogen dioxide; $\mathrm{SO}_{2}$, sulfur dioxide

air pollution. However, there is lack of consistent results for sex differences in health effects of various air pollutants. Many similar studies conducted in Beijing for asthma children [43], in Ningbo for respiratory infections children [44], in Jinan for outpatient respiratory diseases [45] and in Hanoi for children lower respiratory infections [18] found that there was no obvious difference between boys and girls. Thus, additional studies are needed to clarify whether there are sex differences for the associations between air pollutants and respiratory diseases among children. In age difference, we found younger children ( $0-3$ years) were more vulnerable to air pollution. A study in Ningbo for pneumonia observed stronger associations between air pollutants and children under 5 years [17]. The study in Hanoi also showed positive relationship between airborne particles and daily 
(A) $\mathrm{PM}_{10}$


(B) $\mathrm{PM}_{2.5}$
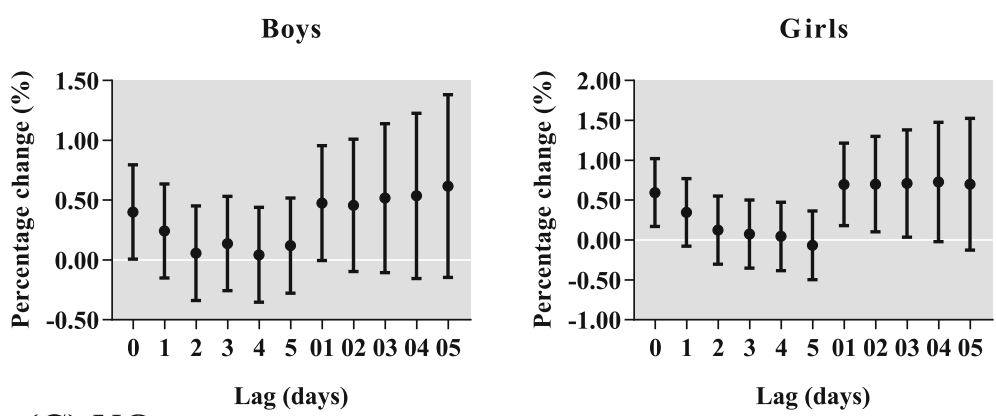

(C) $\mathrm{NO}_{2}$

Boys

Girls

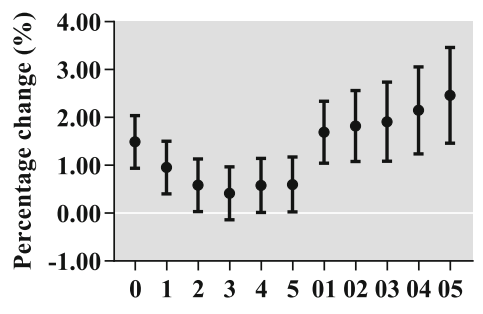

(D) $\mathrm{SO}_{2}$

Lag (days)

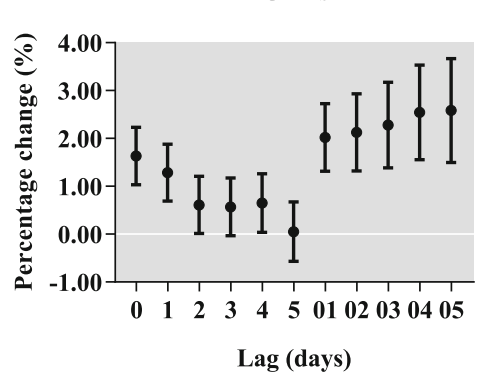

Boys

Girls
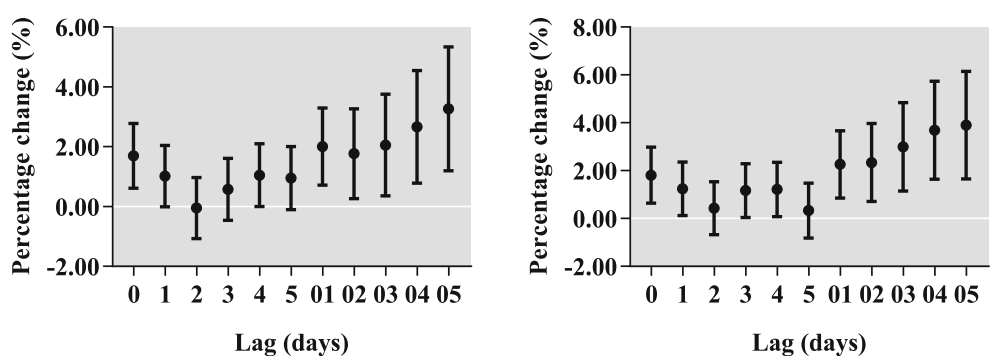

Fig. 6 Percentage change (95\% confidence interval) of daily children outpatient visits caused by respiratory diseases per $10 \mu \mathrm{\mu g} / \mathrm{m}^{3}$ increase in concentrations of air pollutants stratified by sex for different lag days in the single-pollutant models in Lanzhou, China, during 2014-2016. PM 2.5 , particulate matter with aerodynamic diameter $\leq 2.5 \mu \mathrm{m} ; \mathrm{PM}_{10}$, particulate matter with aerodynamic diameter $\leq 10 \mu \mathrm{m} ; \mathrm{NO}_{2}$, nitrogen dioxide; $\mathrm{SO}_{2}$, sulfur dioxide 
(A) $\mathbf{P M}_{10}$

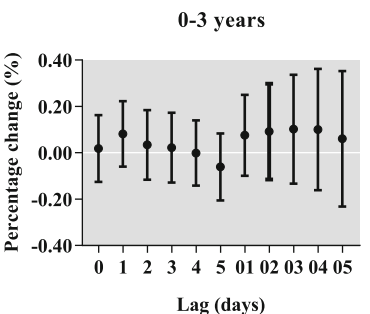

(B) $\mathbf{P M}_{2.5}$

0-3 years

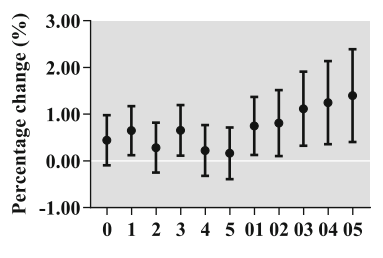

Lag (days)

(C) $\mathrm{NO}_{2}$

0-3 years

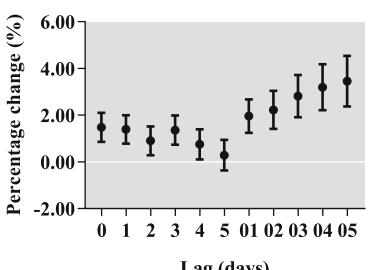

(D) $\mathrm{SO}_{2}$

0-3 years

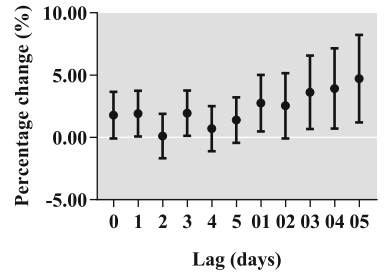

4-6 years

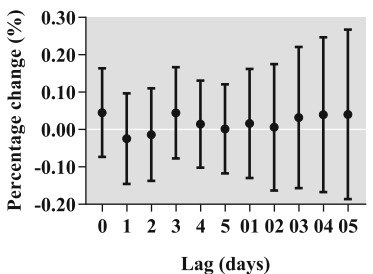

4-6 years

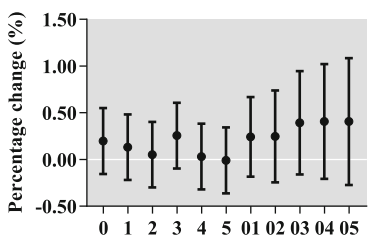

Lag (days)

4-6 years

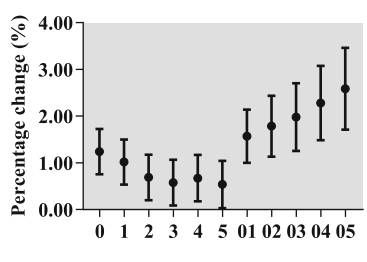

Lag (days)

4-6 years

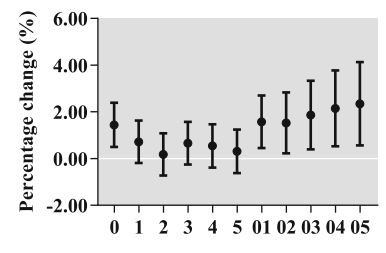

Lag (days)
7-13 years

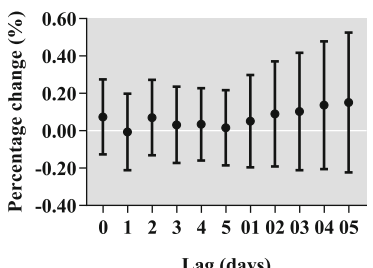

Lag (days)

7-13 years

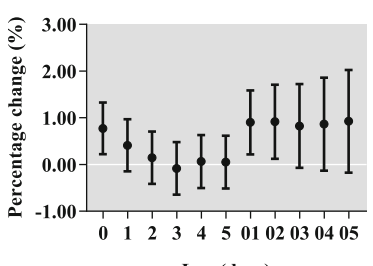

Lag (days)

7-13 years

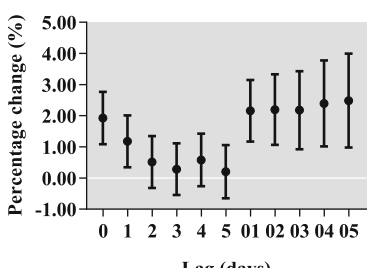

Lag (days)

7-13 years

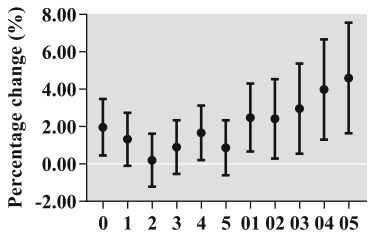

Lag (days)

Fig. 7 Percentage change (95\% confidence interval) of daily children outpatient visits caused by respiratory diseases per $10 \mu \mathrm{\mu g} / \mathrm{m}^{3}$ increase in concentrations of air pollutants stratified by age for different lag days in the single-pollutant models in Lanzhou, China, during 2014-2016. PM 2.5 , particulate matter with aerodynamic diameter $\leq 2.5 \mu \mathrm{m} ; \mathrm{PM}_{10}$, particulate matter with aerodynamic diameter $\leq 10 \mu \mathrm{m} ; \mathrm{NO}_{2}$, nitrogen dioxide; $\mathrm{SO}_{2}$, sulfur dioxide

hospital admission for respiratory diseases among children aged $<5$ years [46]. It is generally recognized that this high vulnerability among younger children can be attributed to their immature lungs, higher breathing rate [47] and predominantly oral breathing characteristics [48], which increased their exposure and susceptibility to respiratory infections. These factors, combined with the underdeveloped immune function, may add together to make infant and younger children more susceptible to air pollutants.

In the present study, the descriptive results showed that the concentrations of air pollutants in Lanzhou were higher in the cold season, which is consistent with the study in Shennongjia [49]. Previous study suggested winter was the most polluted season [50]. In Northeastern and Northwestern China, due to a specific cold climate in winter and regional living habits, air pollution mainly comes from coal burning, motor vehicles and industrial production [51, 52]. Lanzhou is located in Northwestern China with a narrow and long valley basin and low winds, stable stratification especially inversion, which blocks the air streams and makes the pollutants difficult to disperse [53]. In addition, coal use in the winter also increases the level of air pollution [36]. These 
(A) $\mathbf{P M}_{10}$
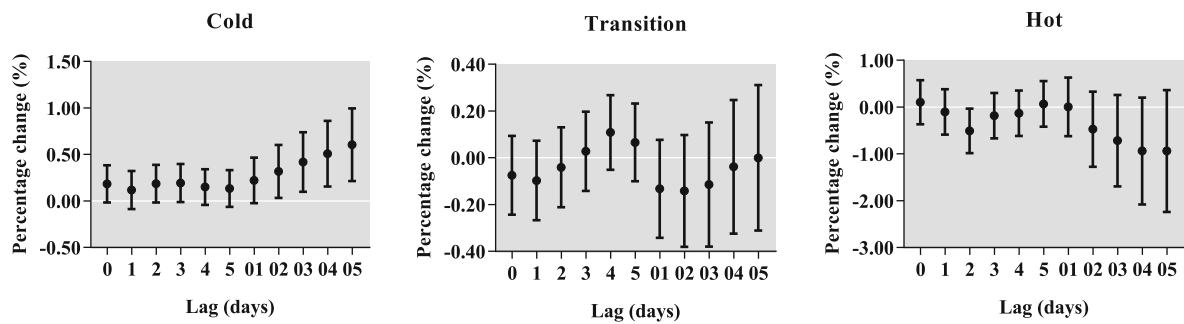

(B) $\mathbf{P M}_{2.5}$

Cold

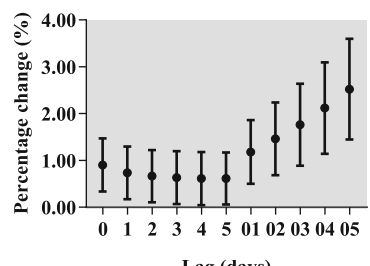

(C) $\mathrm{NO}_{2}$

Cold

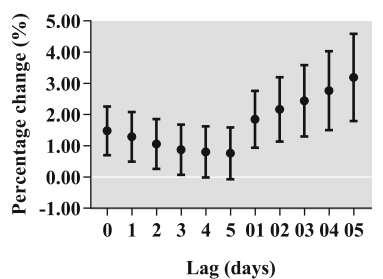

(D) $\mathrm{SO}_{2}$

Cold

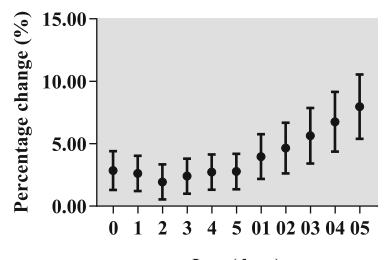

Transition

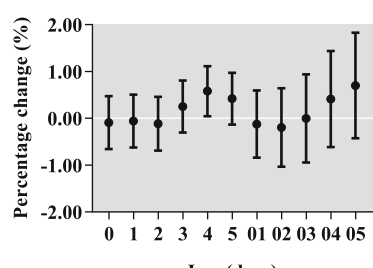

Transition

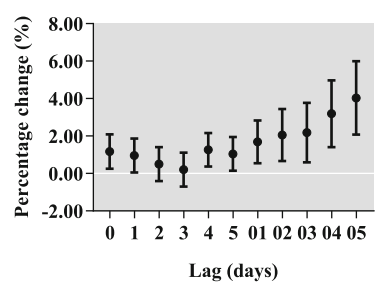

Transition

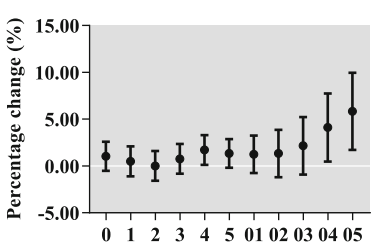

Lag (days)
Hot

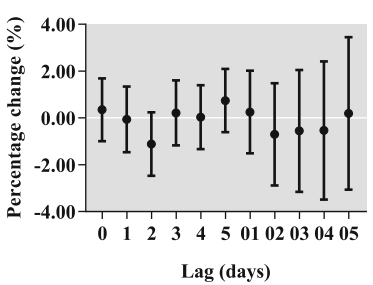

Hot

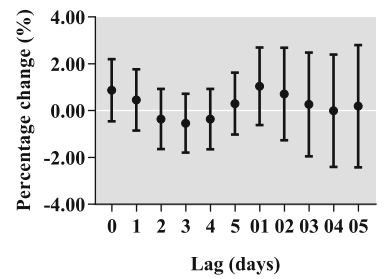

Hot

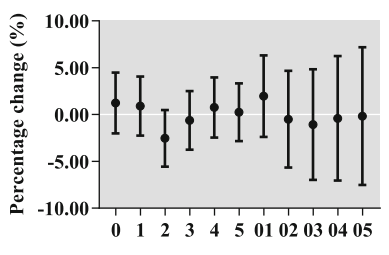

Lag (days)

Fig. 8 Percentage change (95\% confidence interval) of daily children outpatient visits caused by respiratory diseases per $10 \mu \mathrm{g} / \mathrm{m}^{3}$ increase in concentrations of air pollutants stratified by season for different lag days in the single-pollutant models in Lanzhou, China, during $2014-2016$. $\mathrm{PM}_{2.5}$, particulate matter with aerodynamic diameter $\leq 2.5 \mu \mathrm{m} ; \mathrm{PM}_{10}$, particulate matter with aerodynamic diameter $\leq 10 \mu \mathrm{m} ; \mathrm{NO}_{2}$, nitrogen dioxide; $\mathrm{SO}_{2}$, sulfur dioxide

Table 3 Pearson correlation analysis of pollutants

\begin{tabular}{lllll}
\hline Pollutants & $\mathrm{PM}_{2.5}$ & $\mathrm{PM}_{10}$ & $\mathrm{SO}_{2}$ & $\mathrm{NO}_{2}$ \\
\hline $\mathrm{PM}_{2.5}$ & 1.00 & & & \\
$\mathrm{PM}_{10}$ & $0.73^{*}$ & 1.00 & & \\
$\mathrm{SO}_{2}$ & $0.60^{*}$ & $0.33^{*}$ & 1.00 & \\
$\mathrm{NO}_{2}$ & $0.57^{*}$ & $0.39^{*}$ & $0.53^{*}$ & 1.00 \\
${ }^{*} \mathrm{P}<0.05$ & & & &
\end{tabular}

factors may lead the air pollution of Lanzhou to be the most severe in cold seasons. This may explain why we found the greatest effects of $\mathrm{PM}_{10}, \mathrm{PM}_{2.5}$ and $\mathrm{SO}_{2}$ on children respiratory outpatients in the cold season. However, the result for $\mathrm{NO}_{2}$ agrees with the similar study in Shijiazhuang [23], but is inconsistent with the study in Yichang [37]. This may also be explained by the different source of air pollutants among these cities, $\mathrm{NO}_{2}$ was also the major air pollutant in Yichang but not in Lanzhou or Shijiazhuang.

Our study has several limitations. First, the study only used the data of 3 years due to limited data accessibility 
Table 4 Percentage change ( $95 \%$ confidence interval) of total children respiratory outpatients per $10 \mu \mathrm{g} / \mathrm{m}^{3}$ increase in concentrations of pollutants in the single and two-pollutant models

\begin{tabular}{lll}
\hline Pollutants & Single- and Two-pollutant models & Estimates \\
\hline $\mathrm{PM}_{10}$ & $\mathrm{PM}_{10}$ & $0.06(-0.18,0.31)$ \\
& $\mathrm{PM}_{10}+\mathrm{NO}_{2}$ & $-0.12(-0.38,0.13)$ \\
& $\mathrm{PM}_{10}+\mathrm{SO}_{2}$ & $-0.04(-0.29,0.22)$ \\
$\mathrm{PM}_{2.5}$ & $\mathrm{PM}_{2.5}$ & $0.64(-0.10,1.38)$ \\
& $\mathrm{PM}_{2.5}+\mathrm{NO}_{2}$ & $-0.47(-1.32,0.38)$ \\
& $\mathrm{PM}_{2.5}+\mathrm{SO}_{2}$ & $-0.08(-0.94,0.79)$ \\
$\mathrm{NO}_{2}$ & $\mathrm{NO}_{2}$ & $\mathbf{2 . 5 0}(\mathbf{1 . 5 4 , 3 . 4 8 )}$ \\
& $\mathrm{NO}_{2}+\mathrm{PM}_{10}$ & $\mathbf{2 . 6 4}(\mathbf{1 . 6 3}, \mathbf{3 . 6 5})$ \\
& $\mathrm{NO}_{2}+\mathrm{PM}_{2.5}$ & $\mathbf{2 . 8 3}(\mathbf{1 . 7 0 , 3 . 9 7 )}$ \\
& $\mathrm{NO}_{2}+\mathrm{SO}_{2}$ & $\mathbf{2 . 1 7}(\mathbf{1 . 1 0 , 3 . 2 6 )}$ \\
& $\mathrm{SO}_{2}$ & $\mathbf{3 . 5 0}(\mathbf{1 . 5 1}, \mathbf{5 . 5 3})$ \\
$\mathrm{SO}_{2}$ & $\mathrm{SO}_{2}+\mathrm{PM}_{10}$ & $\mathbf{3 . 5 7}(\mathbf{1 . 5 2 , 5 . 6 5 )}$ \\
& $\mathrm{SO}_{2}+\mathrm{PM}_{2.5}$ & $\mathbf{3 . 6 2}(\mathbf{1 . 2 6 , 6 . 0 3})$ \\
& $\mathrm{SO}_{2}+\mathrm{NO}_{2}$ & $\mathbf{1 . 4 9}(-0.68,3.70)$ \\
\hline
\end{tabular}

$P M_{2.5}$ particulate matter with aerodynamic diameter $\leq 2.5 \mu \mathrm{m}, P M_{10}$ particulate matter with aerodynamic diameter $\leq 10 \mu \mathrm{m}, \mathrm{NO}_{2}$ nitrogen dioxide, $\mathrm{SO}_{2}$ sulfur dioxide. Six-day moving average (lag 05 ) concentrations of pollutants were used. Bold values denote significant differences

and availability, which may not be abundantly enough to evaluate the effects of air pollution on child respiratory outpatients, but we at least provide some hypothesis from a specific topography with an arid climate and large sample. Second, the air pollution data were collected from only four monitoring stations, the average value of which may not be strong enough to represent the real condition of air quality in Lanzhou. Thus, there should be data from more monitoring stations of Lanzhou. Third, unknown or unmeasured confounders such as indoor air pollution, second-hand smoke exposure and so on may exist and affect the associations. Therefore, all these limitations should be solved in future studies.

\section{Conclusions}

Our results indicate that the air pollution exposure may account for the increased risk of outpatient visits for respiratory diseases among children in Lanzhou, particularly for younger children and in the cold season. To our knowledge, this is the first study to investigate the shortterm effects of air pollution on child respiratory morbidity based on the large population in Northwestern China. The estimated percent changes may be helpful to monitor the disease burden caused by air pollution in Lanzhou among children and strengthen the urgency for controlling air pollution in Lanzhou. Since children are much more susceptible to air pollution, more urgent strategies will be needed to deal with the higher level of respiratory diseases among children, like promoting the use of personal protective equipment (e.g., respirators, air purifiers) and avoiding outdoor activities during heavily polluted weathers of Lanzhou.

\section{Abbreviations \\ $\mathrm{PM}_{10}$ : Particulate matter with aerodynamic diameter $\leq 10 \mu \mathrm{m}$; \\ $\mathrm{PM}_{2.5}$ : Particulate matter with aerodynamic diameter $\leq 2.5 \mu \mathrm{m} ; \mathrm{NO}_{2}$ : Nitrogen dioxide; $\mathrm{SO}_{2}$ : Sulfur dioxide; GAM: Generalized additive model; $\mathrm{Cl}$ : Confidence interval; RR: Relative risk \\ Acknowledgements \\ Not applicable. \\ Authors' contributions \\ $\mathrm{BL}$, JPN and YLM contributed to idea formulation, study design, data preparation, data analysis, reporting results, data interpretation, and writing of the manuscript. LY and JTL contributed to data preparation and data analysis. XTH and LYL contributed to study design and interpretation of the data. All authors have seen and approved the final version. \\ Funding \\ This work was supported by the National Natural Science Foundation of China (4187050043), the foundation of the Ministry of Education Key Laboratory of Cell Activities and Stress Adaptations, Lanzhou University, China (Izujbky-2020-sp21). Chengguan Science and Technology Planning Project, Lanzhou, China (2017SHFZ0043).}

\section{Availability of data and materials}

The datasets used and/or analyzed during the current study are not publicly available but are available from the corresponding author on reasonable request.

\section{Ethics approval and consent to participate}

The environmental data were collected from open access websites, so the consent to participate was not applicable. The hospital admission data were obtained and proved by Lanzhou center for disease control and prevention with official permission. The study protocol including data using was approved by the ethics committee of Lanzhou University (Project identification code: IRB190612-1).

\section{Consent for publication}

Not applicable.

\section{Competing interests}

The authors declare that they have no conflict of interest.

\section{Author details}

${ }^{1}$ Institute of Occupational Health and Environmental Health, School of Public Health, Lanzhou University, Lanzhou, Gansu 730000, People's Republic of China. 'ansu Provincial Maternity and Child Health Care Hospital, Lanzhou, Gansu 730000, People's Republic of China. ${ }^{3}$ Shanghai Typhoon Institute, China Meteorological Administration, Shanghai 200030, China. ${ }^{4}$ Shanghai Key Laboratory of Meteorology and Health, Shanghai Meteorological Bureau, Shanghai 200030, China.

Received: 7 October 2019 Accepted: 17 May 2020

Published online: 02 June 2020

\section{References}

1. WHO. World Health Statistics 2018: Monitoring health for the SDGs, vol. 2020; 2018.

2. Nakao M, Ishihara Y, Kim C, Hyun I. The impact of air pollution, including Asian sand dust, on respiratory symptoms and health-related quality of life in outpatients with chronic respiratory disease in Korea: a panel study. J Prev Med Public Health. 2018:51(3):130-9.

3. Wanka ER, Bayerstadler A, Heumann C, Nowak D, Jörres RA, Fischer R. Weather and air pollutants have an impact on patients with respiratory diseases and breathing difficulties in Munich, Germany. Int J Biometeorol. 2014;58(2):249-62 
4. Slama A, Śliwczyński A, Woźnica J, Zdrolik M, Wiśnicki B, Kubajek J, Turżańska-Wieczorek O, Gozdowski D, Wierzba W, Franek E. Impact of air pollution on hospital admissions with a focus on respiratory diseases: a time-series multi-city analysis. Environ Sci Pollut R. 2019;26(17):16998-7009.

5. Kim S, Peel JL, Hannigan MP, Dutton SJ, Sheppard L, Clark ML, Vedal S. The temporal lag structure of short-term associations of fine particulate matter chemical constituents and cardiovascular and respiratory hospitalizations. Environ Health Persp. 2012;120(8):1094-9.

6. Sinclair AH, Edgerton ES, Wyzga R, Tolsma D. A two-time-period comparison of the effects of ambient air pollution on outpatient visits for acute respiratory illnesses. J Air Waste Manag Assoc. 2010;60(2):163-75.

7. Greenberg N, Carel R, Portnov BA. Air pollution and respiratory morbidity in Israel: a review of accumulated empiric evidence. Isr Med Assoc J. 2015; 17(7):445-50.

8. Vodonos A, Friger M, Katra I, Avnon L, Krasnov H, Koutrakis P, Schwartz J, Lior O, Novack V. The impact of desert dust exposures on hospitalizations due to exacerbation of chronic obstructive pulmonary disease. Air Quality, Atmosphere \& Health. 2014;7(4):433-9.

9. Wang K, Chau T. An association between air pollution and daily outpatient visits for respiratory disease in a heavy industry area. PLoS One. 2013;8(10): e75220.

10. Wang C, Feng L, Chen K. The impact of ambient particulate matter on hospital outpatient visits for respiratory and circulatory system disease in an urban Chinese population. Sci Total Environ. 2019;666:672-9.

11. Mo Z, Fu Q, Zhang L, Lyu D, Mao G, Wu L, Xu P, Wang Z, Pan X, Chen Z, et al. Acute effects of air pollution on respiratory disease mortalities and outpatients in southeastern China. Sci Rep-Uk. 2018;8(1):1-9.

12. Pan H, Chen C, Sun H, Ku M, Liao P, Lu K, Sheu J, Huang J, Pai J, Lue K Comparison of the effects of air pollution on outpatient and inpatient visits for asthma: a population-based study in Taiwan. PLoS One. 2014;9(5):1-19.

13. Sunyer J. The neurological effects of air pollution in children. Eur Respir J. 2008;32(3):535-7.

14. Alderete TL, Habre R, Toledo-Corral CM, Berhane K, Chen Z, Lurmann FW, Weigensberg MJ, Goran MI, Gilliland FD. Longitudinal associations between ambient air pollution with insulin sensitivity, beta-cell function, and adiposity in Los Angeles Latino children. Diabetes. 2017;66(7):1789-96.

15. Chen C, Chan C, Chen B, Cheng T, Leon GY. Effects of particulate air pollution and ozone on lung function in non-asthmatic children. Environ Res. 2015;137:40-8

16. Chen Z, Cui L, Cui X, Li X, Yu K, Yue K, Dai Z, Zhou J, Jia G, Zhang J. The association between high ambient air pollution exposure and respiratory health of young children: a cross sectional study in Jinan, China. Sci Total Environ. 2019;656:740-9.

17. Li D, Wang J, Zhang Z, Shen P, Zheng P, Jin M, Lu H, Lin H, Chen K. Effects of air pollution on hospital visits for pneumonia in children: a two-year analysis from China. Environ Sci Pollut R. 2018;25(10):10049-57.

18. Nhung NTT, Schindler C, Dien TM, Probst-Hensch N, Perez L, Künzli N. Acute effects of ambient air pollution on lower respiratory infections in Hanoi children: an eight-year time series study. Environ Int. 2018;110:139-48.

19. Wise J. Better air quality reduces respiratory symptoms among children in southern California. BMJ. 2016;353:i2083.

20. WHO. Ambient (outdoor) air quality and health, vol. 2019: https://www.who. int/en/news-room/fact-sheets/detail/ambient-(outdoor)-air-quality-andhealth; 2018.

21. Chai G, He H, Sha Y, Zhai G, Zong S. Effect of PM2.5 on daily outpatient visits for respiratory diseases in Lanzhou, China. Sci Total Environ. 2019;649: 1563-72.

22. Guan Q, Liu Z, Yang L, Luo H, Yang Y, Zhao R, Wang F. Variation in PM2.5 source over megacities on the ancient silk road, northwestern China. J Clean Prod. 2019;208:897-903.

23. Song J, Lu M, Zheng L, Liu Y, Xu P, Li Y, Xu D, Wu W. Acute effects of ambient air pollution on outpatient children with respiratory diseases in Shijiazhuang, China. Bmc Pulm Med. 2018;18(1):1-10.

24. National Bureau Of Statistics D. Gansu Development Yearbook for 2018, vol. 2019; 2018.

25. Zhang Y, Kang S. Characteristics of carbonaceous aerosols analyzed using a multiwavelength thermal/optical carbon analyzer: a case study in Lanzhou City. Science China Earth Sciences. 2019;62(2):389-402.

26. Dominici F, McDermott A, Zeger SL, Samet JM. On the use of generalized additive models in time-series studies of air pollution and health. Am J Epidemiol. 2002;156(3):193-203.
27. Zhao Y, Hu J, Tan Z, Liu T, Zeng W, Li X, Huang C, Wang S, Huang Z, Ma W. Ambient carbon monoxide and increased risk of daily hospital outpatient visits for respiratory diseases in Dongguan, China. Sci Total Environ. 2019; 668:254-60

28. Li Q, Yang Y, Chen R, Kan H, Song W, Tan J, Xu F, Xu J. Ambient air pollution, meteorological factors and outpatient visits for eczema in Shanghai, China: a time-series analysis. Int J Env Res Pub He. 2016;13(11):110.

29. Guo Q, Liang F, Tian L, Schikowski T, Liu W, Pan X. Ambient air pollution and the hospital outpatient visits for eczema and dermatitis in Beijing: a time-stratified case-crossover analysis. Environ Sci. 2019;21(1):163-73.

30. Liu $Z$, Jin $Y$, Jin $H$. The effects of different space forms in residential areas on outdoor thermal comfort in severe cold regions of China. Int J Env Res Pub He. 2019;16(20):3960

31. Duan Y, Liao Y, Li H, Yan S, Zhao Z, Yu S, Fu Y, Wang Z, Yin P, Cheng J, et al Effect of changes in season and temperature on cardiovascular mortality associated with nitrogen dioxide air pollution in Shenzhen, China. Sci Total Environ. 2019;697:134051.

32. Stasistics LMBO. Analysis of population development of Lanzhou since the 13th five-year plan period, vol. 2020; 2019.

33. Xia X, Zhang A, Liang S, Qi Q, Jiang L, Ye Y. The association between air pollution and population health risk for respiratory infection: a case study of Shenzhen, China. Int J Env Res Pub He. 2017;14(9):950.

34. Li YR, Xiao CC, Li J, Tang J, Geng XY, Cui LJ, Zhai JX. Association between air pollution and upper respiratory tract infection in hospital outpatients aged 0-14 years in Hefei, China: a time series study. Public Health. 2018;156:92100.

35. Zhang H, Niu Y, Yao Y, Chen R, Zhou X, Kan H. The impact of ambient air pollution on daily hospital visits for various respiratory diseases and the relevant medical expenditures in Shanghai, China. Int J Env Res Pub He. 2018;15(3):1-10.

36. Su Y, Sha Y, Zhai G, Zong S, Jia J. Comparison of air pollution in Shanghai and Lanzhou based on wavelet transform. Environ Sci Pollut R. 2019;26(17): 16825-34.

37. Liu Y, Xie S, Yu Q, Huo X, Ming X, Wang J, Zhou Y, Peng Z, Zhang H, Cui X, et al. Short-term effects of ambient air pollution on pediatric outpatient visits for respiratory diseases in Yichang city, China. Environ Pollut. 2017;227: $116-24$.

38. Yang Z, Li X, Deng J, Wang H. Stable sulfur isotope ratios and water-soluble inorganic compositions of PM10 in Yichang City, Central China. Environ Sci Pollut R. 2015;22(17):13564-72.

39. Jiang Y, Shi L, Guang A, Mu Z, Zhan H, Wu Y. Contamination levels and human health risk assessment of toxic heavy metals in street dust in an industrial city in Northwest China. Environ Geochem HIth. 2018;40(5SI): 2007-20.

40. Guarnieri M, Balmes JR. Outdoor air pollution and asthma. Lancet. 2014 383(9928):1581-92.

41. Liu J, Ruan Y, Wu Q, Ma Y, He X, Li L, Li S, Niu J, Luo B. Has the mortality risk declined after the improvement of air quality in an ex-heavily polluted Chinese city-Lanzhou? Chemosphere. 2020;242:125196.

42. Becklake MR, Kauffmann F. Gender differences in airway behaviour over the human life span. Thorax. 1999;54(12):1119-38.

43. Hua J, Yin Y, Peng L, Du L, Geng F, Zhu L. Acute effects of black carbon and PM2.5 on children asthma admissions: a time-series study in a Chinese city. Sci Total Environ. 2014:481:433-8.

44. Zheng P, Wang J, Zhang Z, Shen P, Chai P, Li D, Jin M, Tang M, Lu H, Lin H, et al. Air pollution and hospital visits for acute upper and lower respiratory infections among children in Ningbo, China: a time-series analysis. Environ Sci Pollut R. 2017;24(23):18860-9.

45. Wang S, Li Y, Niu A, Liu Y, Su L, Song W, Liu J, Liu Y, Li H. The impact of outdoor air pollutants on outpatient visits for respiratory diseases during 2012-2016 in Jinan. China Resp Res. 2018;19(1):1-8.

46. Luong LMT, Phung D, Sly PD, Morawska L, Thai PK. The association between particulate air pollution and respiratory admissions among young children in Hanoi, Vietnam. Sci Total Environ. 2017;578:249-55.

47. Sigmund E, De Ste CM, Miklankova L, Fromel K. Physical activity patterns of kindergarten children in comparison to teenagers and young adults. Eur J Public Health. 2007:17(6):646-51.

48. Esposito S, Tenconi R, Lelii M, Preti V, Nazzari E, Consolo S, Patria MF. Possible molecular mechanisms linking air pollution and asthma in children. Bmc Pulm Med. 2014;14:1-8. 
49. Liu C, Liu Y, Zhou Y, Feng A, Wang C, Shi T. Short-term effect of relatively low level air pollution on outpatient visit in Shennongjia, China. Environ Pollut. 2019;245:419-26.

50. Chen $\mathrm{W}$, Yan L, Zhao H. Seasonal variations of atmospheric pollution and air quality in Beijing. Atmosphere-Basel. 2015;6(11):1753-70.

51. Xiao Q, Ma Z, Li S, Liu Y. The impact of winter heating on air pollution in China. PLoS One. 2015;10(1):e117311.

52. He J, Lu S, Yu Y, Gong S, Zhao S, Zhou C. Numerical simulation study of winter pollutant transport characteristics over Lanzhou City, Northwest China. Atmosphere-Basel. 2018;9(10):1-8.

53. Chu PC, Chen Y, Lu S, Li Z, Lu Y. Particulate air pollution in Lanzhou China. Environ Int. 2008;34(5):698-713

\section{Publisher's Note}

Springer Nature remains neutral with regard to jurisdictional claims in published maps and institutional affiliations.

Ready to submit your research? Choose BMC and benefit from:

- fast, convenient online submission

- thorough peer review by experienced researchers in your field

- rapid publication on acceptance

- support for research data, including large and complex data types

- gold Open Access which fosters wider collaboration and increased citations

- maximum visibility for your research: over $100 \mathrm{M}$ website views per year

At $\mathrm{BMC}$, research is always in progress.

Learn more biomedcentral.com/submissions 